\title{
Public Childcare Expansion and Changing Gender Ideologies of Parents in Germany
}

Gundula Zoch $^{1} \quad$ Pia S. Schober ${ }^{2}$

July 2017. Unrefereed manuscript. Pre-print.

Published in: Journal of Marriage and Family 8o (4): 1020-39. (revised version)

\begin{abstract}
This study investigates whether the expansion of public childcare in Germany has been associated with individual-level change in parents' gender ideologies. We extend the literature by developing and testing a theoretical framework of short-term impact of family policy institutions on attitude change over the life course. The analysis links the German Family Panel pairfam (2008 to 2015) with administrative records on childcare provision at county level and applies fixed effects panel models. Our findings show that the childcare expansion has been associated with moderate changes towards less traditional gender ideologies only among mothers in West Germany and mostly so among mothers without a college degree. Surprisingly, in East Germany, we found tentative evidence of more traditional gender ideologies among mothers without a college degree as the childcare reform unfolded. The results provide evidence that policy reforms may alter gender ideologies also in the short-term over the life course.
\end{abstract}

Keywords: child care arrangements, maternal employment, family policy, family roles, fixed effects models, life events and/or transitions

\footnotetext{
${ }^{1}$ Gundula Zoch, Bamberg Graduate School of Social Sciences, University of Bamberg, Feldkirchenstr. 21, 96045 Bamberg, Germany

2 Pia S. Schober, University of Tübingen, Wilhelmstrasse 36, 72074 Tübingen, Germany, and German Institute of Economic Research (DIW Berlin), Mohrenstrasse 58, 10117 Berlin, Germany
} 
Over the past decades, many Western countries have invested increasingly in family policies to facilitate the combination of employment and childcare and to reduce persistent gender differences (International Network of Leave Policies \& Research, 2016). A large body of international economic and sociological literature has focused on how the length of leave entitlements, compensation rates, and fathers' quota or the availability and costs of childcare services impact the gender division of domestic work and paid employment (e.g. Geyer, Haan, \& Wrohlich, 2015; Hook, 2006; Pettit \& Hook, 2005). Comparative studies have highlighted the importance of family policy institutions not only for shaping opportunity structures but also for influencing gender culture within society (e.g., Böckmann, Misra, \& Budig, 2015; Grunow \& Evertsson, 2016; Sjöberg, 2004). However, few studies have investigated whether and through which channels family policy reforms may alter social attitudes and norms in the short-term. The recent expansion of childcare provision in Germany provides a unique opportunity to investigate the short-term impact of childcare reforms on gender ideologies over the life course.

Investigating gender ideologies is important to understand persistent gender inequalities. Gender ideologies have been found to correlate with related behavior, such as maternal labor supply, career trajectories and the gender division of domestic labor (see Davis \& Greenstein, 2009 and Steiber \& Haas, 2012 for an overview). A number of crosssectional comparisons of maternal employment (e.g., Böckmann et al., 2015) and gender ideologies (e.g., Sjöberg, 2004) across countries emphasize the institutional context, in particular the availability of affordable non-parental childcare (Ciccia \& Bleijenbergh, 2014; Steiber \& Haas, 2012). In addition, recent longitudinal studies suggest a significant attitude change due to life course events, such as marriage, childbirth, child's sex or death of a relative (e.g., Baxter, Buchler, Perales, \& Western, 2015; Brooks \& Bolzendahl, 2004; Author, 2012). These studies provide evidence that the formation of gender ideologies is not completed in early adolescence but remains subject to the influence of later life course events. However, with respect to family policies, little evidence exists as to whether institutional reforms can alter ideologies only in the long-term via cohort replacement or also in the short-term (Ellingsæter, Kitterød, \& Lyngstad, 2017; Gangl \& Ziefle, 2015; Unterhofer \& Wrohlich, 2017).

We contribute to the literature on cultural change over the life course by investigating whether the recent expansion of public childcare places in Germany has been 
associated with a change in gender ideologies. By combining longitudinal individuallevel information on parents' ideologies with annual administrative records on childcare provision at the county level, we exploit regional and temporal variation in the expansion of formal childcare provision and investigate whether greater childcare availability increases the acceptance of maternal employment due to role exposure or normative policy effects. By investigating the relationship of the expansion of childcare services with ideologies separately for East and West German mothers and fathers, respectively, we are able to examine whether different pre-reform cultures regarding maternal employment and formal childcare use may moderate any short-term policy effects.

\section{Background: Institutional and Cultural Context in East and West Germany}

Persistent East-West differences in the acceptance of maternal employment and formal childcare have long been explained by different family policies before the German reunification. Before 1990, the institutional setting in West Germany was characterized by joint taxation for couples, family health insurance, long but low-paid parental leave entitlements, and a lack of public childcare services. This has frequently been classified as supported familialism (Hook, 2015) and is considered to suppress employment of second earners and reinforce gender inequality. New mothers tended to interrupt their employment for several years and often returned to the labor market only part-time. By contrast, in the German Democratic Republic shorter parental leave and extensive provision of formal care for very young children encouraged a fast and full-time return to the labor market of mothers (Rosenfeld, Trappe, \& Gornick, 2004). Since reunification, employment trends among mothers with young children have converged somewhat and part-time employment has become the most prevalent arrangement to combine employment and family care in both regions (Konietzka \& Kreyenfeld, 2010). Yet the historical differences are still reflected in longer employment interruption durations, lower maternal employment participation and more conservative attitudes of parents towards maternal employment and using formal childcare for young children in West Germany compared to East Germany.

Since the mid-20oos, reforms of parental leave and childcare policies in Germany indicate a paradigm shift from the previous model of supported familialism (Hook, 2015). They aimed at improving the compatibility of employment and family care, speeding up maternal labour market return, and increasing paternal childcare involve- 
ment. Before a major reform in 2007, parents on parental leave were eligible to receive a childrearing benefit of about 300 Euros per month for the first six month and depending on household income, parents could extend this until the child's second birthday. In 2007, the German government introduced an income-related parental leave of twelve months and an individual 'use-it-or-lose-it' entitlement of two months of leave for each parent. As before, each parent has been entitled to three years of leave in total. However, the more generous and income-related compensation for a shorter period provided incentives for faster maternal labor market return.

Furthermore, the recent expansion of public childcare provision for children under three years has increased overall childcare attendance rates tremendously in East and West Germany, albeit starting from a different level. The expansion started with the Day-care Expansion Act (Tagesbetreuungsausbaugesetz) in 2005, which provided extra funding and granted prioritized access for children with parents in employment or education. In addition, the 2008 Child and Youth Welfare Act (Kinderförderungsgesetz) stipulated a legal right to a place in formal care for all children aged one year or older from August 2013. Between 2006 and 2014, the average attendance rate for children aged under three years subsequently increased from 8 to 27 percent in West Germany and from 40 to 52 percent in East Germany (Strunz, 2015). However, these average changes mask great regional variation in attendance rates ranging from 14 to 47 percent in West German counties and from 45 to 63 percent across counties in East Germany in 2014 (Strunz, 2015). These regional variations in the development of childcare provision over time are significantly related to the strength of catholic history, trends in maternal employment, and political priorities of specific parties (Andronescu \& Carnes, 2015). In this study, we exploit these temporal and regional variations in the childcare expansion to identify short-term effects on parental attitude change over the life course.

\section{Previous Studies}

Several comparative studies of a small number of countries or cultural contexts have hinted at the importance of family policy institutions in shaping opportunity structures and cultural ideals regarding maternal employment and adequate care for young children (e.g. Banaszak, 2006; Bauernschuster \& Rainer, 2012; Sjöberg, 2004). These approaches generally assume that beliefs and practices in terms of work-family articulation are formed during childhood in relation to the overall context of parental as well as 
welfare regime socialization and consider them largely stable over the life course. Cultural change therefore is assumed to be driven by cohort replacement (e.g., Baxter et al., 2015; Bolzendahl \& Myers, 2004; Brooks \& Bolzendahl, 2004; Sjöberg, 2004; Steiber \& Haas, 2012).

A few recent comparative studies using (repeated) cross-sectional data consider more direct measures of institutional support for different work-care arrangements to better disentangle compositional differences at the individual level and cultural or policy variations at the macro level (Kangas \& Rostgaard, 2007; Sjöberg, 2004). Based on a cross-sectional comparison of seven European countries, Kangas \& Rostgaard (2007) found that a higher level of formal childcare provision in terms of availability, affordability and quality correlated with greater probability of female employment. Sjöberg (2004) found that more generous family policy institutions which support the dualearner family were associated with more egalitarian attitudes towards maternal employment at the individual level. These studies were unable to estimate any causal effects or disentangle attitude change due to cohort replacement from attitudinal change over the life course.

Although several studies have shown that ideologies are transmitted in childhood and remain relatively stable over time (Cunningham, 2001; Min, Silverstein, \& Lendon, 2012; van Putten, Dykstra, \& Schippers, 2008), there has been additional support for attitude change over the life course. Theories of individual change share the common assumption that altered contexts, lifetime events, or practices can lead to changes in attitudes and beliefs (e.g., Brooks \& Bolzendahl, 2004; Kraaykamp, 2012; Stets \& Burke, 2000), such as the impressionable years hypothesis (Alwin \& Krosnick, 1991), which assumes young adults to have the least stable preferences and to experience substantial attitude change. In line with this, Min et al. (2012) have shown a conditional lagged effect of parental socialization on their children's gender role attitudes. When children reach a certain level of maturity and experience certain lifetime events, gender ideologies which they were previously exposed to might be activated. Thereby, young adults' attitudes are not determined solely by their parents' attitudes but shaped by contextual and interactional dynamics, especially during major life course transitions such as marriage, parenthood, and labor force entry or exit (Alwin \& Krosnick, 1991; Brooks \& Bolzendahl, 2004; Cunningham, 2001). 
A few authors, applying a repeated cross-sectional design, have attempted to disentangle cultural change due to cohort replacement and attitudinal change over the life course, by controlling for period effects or analyzing different periods (e.g., Bolzendahl \& Myers, 2004; Davis \& Greenstein, 2009; Kraaykamp, 2012). By decomposing intercohort and intra-cohort effects, Kraaykamp (2012) has shown considerably larger intracohort effects compared to cohort-change for the increase in gender-egalitarian views in the Netherlands. Some single country longitudinal studies of the UK, Australia, and Germany have also provided evidence of changes in gender ideologies after the transition to parenthood (Baxter et al., 2015; Berrington, Hu, Smith, \& Sturgis, 20o8; Author, 2012). The extent of change appears to correlate with labor market transitions and childcare choices and the extent to which these are in line with prenatal attitudes or constrained by economic and institutional factors (Berrington et al., 2008; Author, 2012). Grunow and Müller (2012) found that East German mothers who were born in the East but living several years in the West prior to childbirth returned to the labor market more slowly than their East German counterparts did, but faster than other West German mothers did. The authors take this as a sign of moderately stable socialization but also cultural adaptation to a different institutional, particularly to the lack in childcare provision, and cultural setting in West Germany. These longitudinal studies, however, were unable to consider direct measures of changes in institutional context, such as childcare services, over time.

To our knowledge, only a few recent studies have examined short-term influences of work-family policy institutions on preferences or attitudes. Based on a surveyexperimental design, Pedulla \& Thébaud (2015) showed that the majority of young adults preferred an egalitarian relationship structure. Particularly women were significantly more likely to choose a more gender-traditional arrangement when facing institutional constraints without supportive policies, such as gendered workplace cultures and policies, which constrain equal sharing of breadwinning, housework, and care giving. Applying a treatment and control design to cross-sectional data from Norway, Kotsadam \& Finseraas (2011) found that the introduction of an individual parental leave entitlement was associated with a more gender equal division of housework and less frequent conflict over household labor 15 years after the reform but was not significantly related to changes in gender ideologies. By applying difference-in-difference estimators, Gangl \& Ziefle (2015) revealed that several reforms increasing the generosity of parental 
leave entitlements in Germany during the 1990s and early 20oos were associated with role exposure and norm setting effects. They provide evidence that parental leave policies resulted in a decline in mothers' work commitment and labor force participation. Unterhofer \& Wrohlich (2017) exploit a quasi-experimental setting of a parental leave reform in 2007 in Germany, which introduce income-related leave reimbursement and a fathers' quota while shortening the duration of paid leave. They found that the reform led to a change towards less traditional gender ideologies among respondents, whose son had a child after the introduction of the father' quota. This suggests that the reform induced also indirect effects through social interaction. With regard to childcare policies, Ellingsaeter et al. (2017) found that a period of substantial increase in childcare availability in Norway has been associated with a considerable increase in the acceptance of formal childcare among all socio-economic groups and in all parts of the country. Yet, they only examined repeated cross-sectional data at two observation times and were unable to consider a direct measure of childcare availability over time.

Our study adds to this research by investigating the effect of greater childcare provision on parents' gender ideologies using a direct measure of public childcare availability. We exploit the temporal and regional variation in the speed at which public childcare has expanded in both East and West Germany to identify potential influences on changing gender ideologies of parents during a critical life course phase in terms of gender relations. We also draw on the long-standing and persistent variation in cultural ideals between East and West Germany and investigate whether the childcare expansion impacted parents' gender ideologies towards maternal employment differently depending on the cultural context.

\section{Conceptual Framework}

We develop a theoretical framework, which integrates the concept of policy feedback effects (Kumlin \& Stadelmann-Steffen, 2014) with sociological and psychological theories of attitude change over the life course. Policy reform effects on gender ideologies are conceptualized as resulting either from role exposure or also from indirect effects through cultural diffusion of new information by media or social networks. We draw on identity theories (Stets \& Burke, 200o) or cognitive dissonance theory (Festinger, 1957) to formulate hypotheses relating to role exposure effects, whereas we use the elabora- 
tion likelihood model (Petty \& Cacioppo, 1986) to consider indirect effects through information processing.

The concept of policy feedback effects has been widely applied when investigating whether citizens' attitudes and beliefs do not only result in future public policies but whether, in addition, these policy changes result in (feedback) effects on citizens' welfare-state-related attitudes (Kumlin \& Stadelmann-Steffen, 2014). We apply this concept in order to explain, how policy change, particularly a change in childcare policies, impact on individual-level attitudes towards maternal employment. The policy feedback literature emphasizes two causal mechanisms to explain the relationship between policy change and the formation of attitudes and social norms: i) psychological adaptations to role exposure and ii) cultural diffusion and norm-setting effects (Gangl \& Ziefle, 2015; Kumlin \& Stadelmann-Steffen, 2014). Policy change, such as the childcare expansion, is more likely to affect individuals' attitudes the greater the policy visibility and the policy proximity. Policy visibility refers to "the degree to which a policy is salient to mass publics", whereas policy proximity is understood as "the extent to which it will affect people's lives" (Ellingsæter et al., 2017, p. 152). Policy proximity, therefore, relates closely to perspectives that consider how individuals adapt their identities because of direct exposure to new roles.

\section{Exposure based approaches.}

According to identity theory and social identity theory (Stets \& Burke, 200o), individuals construct both passively and actively new images of themselves whenever they experience new roles or a change in social category or group, respectively. Frequently such changes occur in the course of life course transitions, including the transition to parenthood or family related employment transitions. According to these exposurebased perspectives, we expect that greater availability of childcare facilities will facilitate maternal labor market re-entry and identification with the role as a working mother. For mothers who are already back at work, a greater childcare provision will enable them to draw on more childcare support and to work longer hours. Due to a change in responsibilities and roles in the family as well as the work sphere, we would expect mothers and their partners to alter their self-concept towards less traditional gender identities and to become more accepting of maternal employment and formal childcare. In addition, one could expect the mediating effect of maternal employment to be par- 
ticularly strong, when family childcare had been the dominant cultural ideal in a region such as West Germany.

Life course events can also lead to change in social attitudes and norm as a result of cognitive dissonance, whenever circumstances are constrained and one's beliefs are at odds with new unchangeable behaviors or arrangements connected to these new circumstances (Festinger, 1957). Some authors have suggested that a lack of affordable childcare services increases cognitive dissonance among young mothers with workoriented values prior to childbirth, raising the likelihood of them adapting their attitudes in line with the more traditional division of labor (Baxter et al., 2015; Author, 2012).The expansion of childcare services will support mothers in re-entering the labor market or increasing their working hours in line with their preferences. This will result in fewer mothers changing their self-concept to identify with the homemaker role after childbirth.

\section{Elaboration likelihood model.}

As a second channel of policy feedback effects, policy visibility to the wider public may be relevant to understanding changes in ideologies following policy reforms. The elaboration likelihood model (Petty \& Cacioppo, 1986) may be used to explain cultural diffusion and norm-setting effects of policy reforms. The model assumes that communication about experiences of significant others or new information may induce attitude change. It further assumes that individuals process information at different levels of thought, called elaboration. It proposes two major routes of persuasion: a central route with a high level of elaboration and a peripheral route with lower levels of elaboration. The central route is used to process information based on arguments and facts, which are carefully elaborated on a high level, whereas information processed on the peripheral route is not carefully elaborated and instead only a rather general message is received. Attitude change induced by centrally processed information is assumed to be longerlasting and predictive of behavior, whereas peripherally processed information is more likely to change attitudes only temporarily.

In Germany, the exceptional increase in childcare provision was accompanied by a sophisticated media strategy (Bujard, 2014) and continued high level of media coverage, supported by at least annual childcare coverage reports of the Federal Statistical office (Federal Statistical Office, 2015). Given that local and regional newspapers dominate in 
Germany (Bundesverband deutscher Zeitungsverleger, 2017), media reporting about rising childcare demand, increasing childcare provision and potential benefits of early education and care for child development are highly likely to correlate with regional variations in the expansion of childcare services. In line with this, an evaluation study of various family policies in Germany showed that about 57 per cent of the total population and about 73 of parents knew about the possibilities of formal care for young children already in 2010 (Haumann, 2014). Furthermore, analyzing the Google Search Trends suggests not only an increase in information supply but also in information demand. Between 2007 and 2016, there seems to be a seasonal as well as positive time trend for the search term "Kindergarten". In addition, Google Trends has registered more search request in West German cities, compared to East Germany (Google Trends, 2017). It can therefore be assumed, that the visibility of the childcare policy change has been high and that the policy change took place in close proximity to the target group of parents with young children. In line with policy feedback theories and the elaboration likelihood model, we expect that the increase in media reporting about formal childcare and in information received from social interactions about the experience of childcare use and employment of mothers with young children has been associated with a change towards growing acceptance of formal childcare and maternal employment.

\section{Hypotheses.}

Based on the theoretical approaches, we expect that the increase in public childcare places is overall positively associated with short-term changes towards less traditional gender ideologies (Hypothesis 1). Following exposure-based theories, we hypothesize that maternal labor market returns will partly mediate the associations of the childcare expansion with less traditional gender culture (Hypothesis 2). We asssume the childcare expansion to have greater policy proximity for mothers compared to fathers, as women are more likely to experience a greater change in roles. Hence, mothers' gender ideologies will be more strongly affected by the policy change (Hypothesis 3). Additionally, a pronounced change in gender ideologies is less likely to occur in regions where gender ideologies have already been less traditional and levels of acceptance of maternal employment and formal care use have already been very high before the childcare expansion. As pre-reform childcare attendance rates in East German counties were much higher than in West Germany, the childcare expansion might have been less visible to 
parents in East Germany. As the level of disagreement with traditional gender ideologies in East Germany is very high in absolute terms and comparable to Nordic countries, a certain degree of saturation might reduce the potential of further short-term changes towards less traditional gender ideologies. Consequently, we expect West German fathers and mothers to show a more pronounced increase in support of egalitarian gender ideologies (Hypothesis 4). Furthermore, even within West Germany the positive effects of greater childcare availability may have been non-linear with larger changes in attitudes among parents in West German counties, which started from a very low initial provision of childcare prior to the reform.

One may also expect heterogeneous effects for mothers with different educational qualifications depending on the prevailing levels of acceptance of maternal employment before the reform. The direction of such differences is, however, difficult to predict apriori. On the one hand, college-educated mothers may have been more affected by the reform, as they increased their disagreement with traditional gender ideologies and their take-up of and exposure to formal childcare more than other groups during the expansion period (Author, 2017). On the other hand, college-educated mothers indicated greater work commitment and acceptance of maternal employment and formal childcare for young children (Drasch, 2013; Gangl \& Ziefle, 2015) and were probably better informed about potential benefits of formal childcare for children already prior to the reform. We will test empirically whether greater initial acceptance of formal childcare use and better information may go hand in hand with less change among highlyeducated parents and offset counteracting effects due to more frequent exposure to childcare institutions and greater potential career gains due to more advantageous labor market opportunities.

\section{Method}

\section{Data and Sample}

To analyze whether the expansion of public childcare provision has been associated with a change in gender culture among parents in East and West Germany, we combined annual administrative records on childcare provision at the county level with individual-level data on attitudes towards maternal employment from the German Family Panel (pairfam) (http://www.pairfam.de), release 7.o (Brüderl et al., 2016). The annual panel survey started with about $\mathbf{1 2 . 0 0 0}$ randomly selected anchor respondents of three 
cohorts (1991-1993, 1981-1983, and 1971-1973) in 2008 (Huinink, Brüderl, Nauck, \& Walper, 2011). Respondents were interviewed around the turn of the year and the multi-actor design provided information on partners, parents and children, if available. Pairfam is the only German panel dataset, which includes longitudinal measures of attitudes on work-family articulation every other year. We used all wave that include items on gender role attitudes, that is wave $1(2008 / 2009)$, wave $3(2010 / 2011)$, wave $5(2012 / 2013)$ and wave $7(2014 / 2015)$.

We restricted the sample to repeatedly observed East and West German mothers and their partners between the ages 20 to 45, who had at least one child, born between October 2008 and April 2015. We excluded teenage mothers, respondents in education and very late births, as we expected dynamics in their attitudes to be driven by special circumstances. As a result, we observed only individuals from the cohorts born from 1981 to 1983 and between 1971 and 1973. To restrict variation in the childcare attendance rate to variation due to the policy reform, we further excluded individuals, who moved to another county within the observation period. In total, we observed mothers in 289 of the 402 counties in Germany. In East Germany, our sample included respondents in 67 of 76 East German counties. Based on all restrictions, our sample consisted of 2,116 mothers (5,051 observations) and 1,431 fathers (3,558 observations) in West Germany and 1,220 mothers (2,946 observations) and 892 fathers (2,269 observations) in East Germany.

\section{Estimation Strategy}

Gender ideologies of mothers and fathers might not only be affected by the variation of childcare provision but also by other regional or individual characteristics which cannot be adequately observed in the data, such as long-standing political differences or personality traits. Ignoring such unobserved factors might bias our estimates when estimating ordinary least square regressions. To reduce the risk of bias, we applied fixed effects panel models, which account for any constant unobserved heterogeneity between the time-varying dependent and independent variables by controlling for the average differences across individuals in any observable or even unobservable factor. By exploiting only within-person variation in the dependent and independent variables, our models examine the relationship between changes in the attitude measures and changes in the provision of childcare as well as other time-variant independent variables. 
As shown in equation (1), we estimated the association between the variation in the annual county-level childcare provision $\boldsymbol{c}_{c t}$ and the variations in attitudes of East and West German mothers and fathers $\boldsymbol{y}_{\boldsymbol{i}}$ living in the same county, respectively. $\boldsymbol{x}_{\boldsymbol{i t}}$ and $\boldsymbol{z}_{\boldsymbol{c} t}$ denote vectors of time-varying control variables at the individual, household and county level, respectively. To account for further influences of time-varying unobserved characteristics, we included period dummies denoted by vector $\boldsymbol{p}_{t} \cdot \boldsymbol{\varepsilon}_{i t}$ represents random variation at each point in time and $\boldsymbol{u}_{\boldsymbol{i}}$ captures the combined effect of time invariant unobserved variables on the dependent variable.

$$
\text { (1) } y_{i t}=\beta_{1 t}+\beta_{2} c_{c t}+\beta_{3} x_{i t}+\beta_{4} z_{c t}+\beta_{5} p_{t}+u_{i}+\varepsilon_{i t}
$$

Due to varying starting levels of childcare provision and acceptance of maternal employment prior to the reform, we ran separate stepwise models for mothers and fathers in West and East Germany, respectively. Our baseline model included only the provision of annual childcare within each county. We then added various time-varying control variables at the individual or household level, which may also induce changes in parents' gender ideologies. Additionally, we controlled for county variation in regional labor markets and in overall economic development, which are likely to influence the provision of childcare and employment participation. In a last step, we tested for a mediating effect of maternal labor market participation. Furthermore, we tested interaction effects to examine whether the effects of the childcare expansion on individual attitude change varied by respondents' education level. We applied design weights to correct for under- or overrepresentation of the two cohorts in the sample as compared to the population (Brüderl et al., 2016).

\section{Operationalization of Dependent and Independent Variables}

\section{Attitudinal measures}

To investigate how the gradual expansion of childcare provision may have impacted parental ideologies over time, we focused on two items relating to attitudes towards maternal employment. At every other wave, pairfam respondents were asked to report their (dis)agreement with the following attitude statements: (1) "Women should be more concerned about family than about career" and (2) "A child under age 6 will suffer from having a working mother". The response scale ranged from 1 (strongly disagree) to 5 (strongly agree), so that higher values represent more traditional attitudes. We ana- 
lyzed the two items considering respondents' attitudes on maternal employment and child well-being separately, as the relationships with the childcare expansion rate varied somewhat. To facilitate comparability of the effect sizes, we standardized the dependent variables in the multivariate analyses.

Table 1 displays average attitude scores for mothers and fathers in East and West Germany across all four periods of observation. For all items, patterns of response revealed significantly more traditional attitudes among parents in West Germany compared to East German parents as well as for fathers in West and East Germany compared to mothers in both parts of Germany. Whereas moderate change in the mean attitude values towards less traditional ideologies was seen for most items among West German parents, in East Germany attitudinal change seemed more ambiguous. Although the means provided little evidence for attitude change, in particular in East Germany, Table 2 displays that the majority of respondents altered their attitudes by at least one point on a five-point scale between two years of observation in both East and West Germany. For example, in West Germany 27 percent of mothers increased and 29 percent of mothers decreased their agreement with the statement that mothers should focus on family rather than career (see Table 2). Among the latter group about 73 per cent of mothers reduced their score by about one unit between two points of observation, whereas 28 per cent even decreased their support by two or more points on the five-point scale. Overall, East German mothers showed the most stable attitudes, whereas West German parents exhibited greater attitudinal change.

\section{Independent variables}

Our key independent variable was the provision of public childcare places at county level, measured as the annual percentage of children aged under three years who were enrolled in publicly funded childcare services in relation to the total population of this age group. Due to substantial excess demand for childcare places (BMFSFJ, 2015), this may also be interpreted as a measure of childcare supply or availability (Andronescu \& Carnes, 2015). The childcare measure included half-day and full-day slots and the observed temporal and the regional variation in the childcare attendance rate in our sample was in line with the overall development of childcare provision (Strunz, 2015). As shown in Table 3, the childcare attendance rate was substantially higher in East German 
counties compared to West German regions and increased gradually over time in both parts of Germany.

We included the following time-varying control variables at the individual and household level: Respondent's age and age squared, age group of the youngest child (o-3 years /4-6 years / 7 years and older), number of children in the household and relationship status, differentiating between living apart together, cohabiting, and married respondents. As employment transitions have been found to correlate with attitudinal changes (Author, 2012) and may mediate the relationship with the childcare expansion, we tested mediating relationships with changes in mothers' employment status, by differentiating between economically inactive, part-time and full-time employed mothers. We also considered a dummy variable of paternal employment and a logged indicator of the monthly net equivalence income adjusted for inflation with base year 2010. Furthermore, we controlled for county variation in regional labor markets and the overall economic situation by including the regional unemployment rate, GDP per capita and the number of public servants per 1000 inhabitants because the public service sector is an important employer, particularly for women. To further account for regional differences in employment opportunities but also disparities in municipal budgets between urban and rural areas as well as more traditional social norms in rural areas, we included an index for the share of a county's population that lives in communities with a very low population density. All regional indicators were annual figures provided by the Regional Database Germany. To account for further unobserved influences, which changed uniformly across regions over time, we included period dummies in all models.

\section{Results}

Table 4 shows results of the fixed effects regressions models of mothers' and fathers' change in gender ideologies in West and East Germany, respectively. The final models include a curvilinear specification of the childcare measure. We present full models including control variables at the individual, household and county level, and year dummy variables, as intermediate modeling steps did not alter the associations with the childcare expansion rate significantly.

Among mothers in West Germany, the expansion in childcare provision was significantly associated with a decrease in the support of the traditionally slanted attitude statements considering women's careers and employment of mothers with preschool 
children (Table 4). The relationships appeared to be curvilinear with greater change towards less traditional ideologies in counties where childcare availability increased from lower levels, i.e. between 5 and 24 percent of childcare take-up, whereas attitudes remained more stable in counties with higher levels of childcare provision above 24 percent. The curvilinear relationship was confirmed by applying a significance test. For fathers in West Germany and for mothers and fathers in East Germany the expansion of childcare availability was not significantly associated with changes in gender ideologies (Table 3).

The significant results for West German mothers provided only partial support for our Hypothesis 1, assuming that the increase in public childcare provision was associated with a change towards less traditional gender ideologies. The effect sizes were modest ranging between 3 and 4 percent of a standard deviation, which correspond to the mostly moderate influences of similar regional-level indicators found in previous studies (e.g., Grunow \& Müller, 2012; Author, 2015; Author, 2016). Among West German mothers, a 10-percentage point increase in childcare provision was associated with a 30 percent decrease in attitudinal support towards less traditional attitudes towards women's careers, which corresponded to a decrease of 0.34 points on the five-point scale. The observed patterns among East German mothers and fathers in Table 4 contradicted Hypothesis 1.East German parents' views regarding women's careers and negative consequences of maternal employment for young children appeared to have become more conservative in counties where childcare provision expanded, although the coefficients were statistically not significant.

Partly in line with Hypothesis 2 and exposure-based explanations, maternal transitions into part-time or full-time employment correlated negatively and employment exits positively with agreement with the traditionally phrased attitude items in several models for mothers and fathers in West Germany (Table 4). However, shifts in attitudes were not consistently stronger for full-time compared to part-time employment across various models. Furthermore, we did not find any mediating or moderating influences of maternal employment status (results of stepwise models and interaction terms are available from the authors). In East Germany, maternal employment transitions were mostly not significantly related to attitudinal changes.

In line with Hypothesis 3, joint models with a gender interaction term confirmed that the increasing childcare provision was associated with significantly greater change 
towards less traditional attitudes on the maternal employment item for mothers than for fathers in West Germany. For the other item and for East Germany, no significant gender differences were found (results available on request).

Hypothesis 4 predicted a greater potential of an expansion of childcare availability to shape attitudes in West Germany than in East Germany. Overall, the results for mother's attitudes towards women's careers were in line with this hypothesis. Joint models with an interaction term for East Germany confirmed a significant change towards less traditional attitudes towards women's careers and consequences of maternal employment for child wellbeing among West German than East German mothers (results available on request). For fathers we did not find any statistically significant differences between East and West Germany.

Table 5 shows the results of models including interaction terms of the childcare attendance rate with a dummy variable indicating whether the respective parent has completed a college degree. The interaction effects suggested that in West Germany the expansion of childcare provision was associated with stronger change towards less traditional attitudes regarding the 'career item' among mothers with lower levels of education compared to college-educated mothers. With regard to East Germany, the negative interaction terms for the 'child item' suggested that the expansion of childcare provision were accompanied by a stronger change towards more egalitarian attitudes among college-educated mothers than among those with lower levels of education, whose attitudes became more traditional. Among fathers in East and West Germany, none of the interaction terms reached statistical significance at the 5-percent level.

\section{Sensitivity Analyses}

As a robustness check we tested a potential mediating influence of actual use of parttime or full-time formal childcare in addition to maternal employment participation. As information on childcare use has only been collected for waves 3 to 7 , we could not include this measure in our main models. Including the use of formal childcare, however, did not alter our main findings for West German mothers (see supplemental Table Az). The association of county-level changes in childcare provision and mothers' attitudes towards the consequences of maternal employment ceased to be significant but this was due to the reduction in sample size. In addition, we tested regional variation in the provision of full-day care slots but did not find any statistically significant associations. 
Moreover, we found no indication that our results are driven by a particular state or a group of federal states. We also checked whether the effects were dominated by attitude change among one of the two cohorts in our sample or varied by youngest child's age, parent's migration background or family status but found no evidence of this.

\section{Concluding Discussion}

Focusing on a major public childcare expansion in Germany, this study provides evidence that a pronounced change in childcare policy has been associated with shortterm changes in individual-level gender ideologies. Our results show that attitudes of West German mothers have become less traditional when experiencing a pronounced increase in childcare provision for under-three-year-olds in counties with low levels of provision (below 25 percent). This effect was driven by mothers without a college degree. By contrast, we find tentative evidence that less educated mothers in East Germany became more traditional in their attitudes towards employment of mothers with young children as childcare provision expanded in their counties. We did not find significant associations for fathers in East and West Germany. Despite a strong association of maternal employment transitions with gender ideologies among parents in West Germany, we did not find that employment transitions mediate or moderate the relationship of the childcare expansion with changes in attitudes. This may point to indirect mechanisms through changes in information about childcare provided by media and social network.

The non-linear relationship with the childcare attendance rate in combination with the finding of a significant difference between West and East Germany may suggest that pronounced attitude change among mothers is more likely in previously relatively traditional contexts. However, as we observe only a few mothers in West German counties with a particularly pronounced increase in childcare availability to more than 35 percent, the curvilinear relationship must be interpreted with caution. Differentiated analysis by parental education revealed stronger change towards less traditional gender role attitudes among lower educated mothers in West Germany. This might suggest that less educated mothers in West Germany who held the most traditional values ( $\mathrm{Au}$ thor, 2017) and showed a comparatively weak attachment to the labor market before the childcare reform (Drasch, 2013; Konietzka \& Kreyenfeld, 2010), were receptive to information about newly available childcare services. In combination with the finding of per- 
sistent and low levels of childcare take-up and employment of less educated mothers (Author, 2017) across the reform period, this result may suggest that their take-up may have been restricted because of priority access to dual-earner parents or due to personal preferences of longer labor market interruptions. The weaker effects on fathers' attitudes in West Germany are in line with the policy effect literature that suggests that changes in childcare practices and associated changes in maternal employment have been of greater impact for mothers' attitudes, who have been more directly affected in their work and care arrangements. While one may assume a certain degree of saturation effect with regard to further short-term changes towards less traditional gender ideologies among East German parents due to the high level of rejection of traditional ideologies prior to the reform, our results surprisingly suggest a change towards more traditional attitudes among mothers with less than college education. Although East German parents probably internalized the dominant role of a working mother through early socialization before the German reunification, they also most likely experienced persistent gender inequalities in the domestic sphere as well as a period of an increased workfamily conflict due to social and economic insecurity following reunification (Banaszak et al. 2006). For some less educated mothers, who held non-traditional values before the reform, further employment-promoting family policies in combination with persistently lower job prospects in the East German labor market might reduce mothers' career ambitions (Author, 2017). In addition, increasing discussions about low levels of quality of formal childcare institutions, particularly in East Germany, might impact negatively on maternal employment transitions and reduce cultural acceptance of formal care use for young children. Previous research has shown a significantly negative association between larger group sizes and maternal employment participation only for mothers in East Germany (Author, 2015).

Overall, our results lend support to the literature on the relevance of life course effects on gender ideologies, particularly to the impressionable years hypothesis (Alwin \& Krosnick, 1991) which assumes that preferences and attitudes of young adults may be subject to considerable change. From a broader perspective, our results confirm previous cross-national comparisons (Kangas \& Rostgaard, 2007; Sjöberg, 2004), which found childcare provisions to predict variations in individuals' gender ideologies. In line with a few recent evaluations of family policy reforms (Ellingsæter et al., 2017; Gangl \& Ziefle, 2015; Kotsadam \& Finseraas, 2011; Unterhofer \& Wrohlich, 2017), this study provides evi- 
dence that family policy reforms, in this case an expansion of childcare services, may facilitate attitude change not only across cohorts but also over the life course. However, our findings emphasize that the impact of this institutional change seems to be of moderate size and concentrated among counties with low levels of previous childcare provision and among respondents with greater policy proximity due to a higher likelihood of role exposure and social interaction with other individuals from the policy target group. In contrast to previous studies, we also find some tentative evidence of retraditionalizing effects of the childcare expansion on less educated mothers within the relatively egalitarian gender culture of East Germany.

Finally, a number of important limitations need to be considered. Firstly, we had to rely on a few traditionally slanted gender role attitude items, which may be less suitable to measures attitude change among a sample with relatively egalitarian views such as East German parents. In addition, attitudinal measures were available only every other year, which might have hindered us from capturing all relevant individual trajectories in order to control for any other potential sources of attitudinal change. We also lacked available data to measure childcare use at all points of observation as well as to consider the quality of regional childcare provision, which, however, remained roughly stable over time (Schilling, 2014). Whereas it is always difficult to disentangle the association between institutional change and cultural change, the longitudinal data in combination with regional measures on childcare provision are unique, to identify attitudinal changes during the corresponding childcare expansion period. However, due to data limitations we were not able to account for any delayed attitudinal change across time, which might have been enforced by the previous change in parental leave legislation. For this reason, our results might capture not only effects of the childcare expansion but also more general social change accompanying the paradigm shift in German family policy. By applying fixed effects regression models, we account for time-invariant unobserved heterogeneity at the individual level, yet, there remains a small risk of bias due to other unobserved time-varying characteristics at the county level which correlate with the childcare expansion. Despite these limitations the study makes an important contribution by emphasizing the relevance of attitudinal change over the life course. As this is one of the first studies investigating the association between social policy and attitude change over the life course, future research should look more into direct as well as indirect mechanisms. These include norm-setting effects, increasing receipt of different 
forms of information from media or social network, and changing exposure and daily practices of how policy reforms may impact attitudes and beliefs.

\section{References}

Alwin, D. F., \& Krosnick, J. A. (1991). Aging, Cohorts, and the Stability of Sociopolitical Orientations Over the Life Span. American Journal of Sociology, 97(1), 169-195. doi:10.1086/229744

Andronescu, C. G., \& Carnes, M. E. (2015). Value coalitions and policy change: The impact of gendered patterns of work, religion and partisanship on childcare policy across German states. Journal of European Social Policy, 25(2), 159-174. doi:10.1177/0958928715573480

Banaszak, L. A. (2006). The Gendering State and Citizens' Attitudes toward Women's Roles: State Policy, Employment, and Religion in Germany. Politics \& Gender, 2(1), 29-55. doi:10.1017/S1743923Xo6060o16

Bauernschuster, S., \& Rainer, H. (2012). Political regimes and the family: how sex-role attitudes continue to differ in reunified Germany. Journal of Population Economics, 25(1), 5-27. doi:10.1007/soo148-011-0370-Z

Baxter, J., Buchler, S., Perales, F., \& Western, M. (2015). A Life-Changing Event: First Births and Men's and Women's Attitudes to Mothering and Gender Divisions of Labor. Social Forces, 93(3), 989-1014. doi:10.1093/sf/sou103

Berrington, A., Hu, Y., Smith, P. W. F., \& Sturgis, P. (2008). A graphical chain model for reciprocal relationships between women's gender role attitudes and labour force participation. Journal of the Royal Statistical Society: Series A (Statistics in Society), 171(1), 89-198. doi:10.1111/j.1467-985X.2007.00510.X

Böckmann, I., Misra, J., \& Budig, M. J. (2015). Cultural and Institutional Factors Shaping Mothers' Employment and Working Hours in Postindustrial Countries. Social Forces, 93(4), 1301-1333. doi:10.1093/sf/sour19

Bolzendahl, C., \& Myers, D. J. (2004). Feminist Attitudes and Support for Gender Equality: Opinion Change in Women and Men, 1974-1998. Social Forces, 83(2), 759-789. doi:10.1353/sof.2005.0005

Brooks, C., \& Bolzendahl, C. (2004). The transformation of US gender role attitudes: cohort replacement, social-structural change, and ideological learning. Social Science Research, 33(1), 106-133. doi:10.1016/So049-089X(03)00041-3

Brüderl, J., Hank, K., Huinink, J., Nauck, B., Neyer, F. J., Walper, S., ... (2016). The German Family Panel (pairfam). doi:10.4232/pairfam.5678.7.0.0

Bujard, M. (2014). Elterngeld: Wie Agenda-Setting und neue Interessenkoalitionen den familienpolitischen Paradigmenwechsel ermöglichten. Retrieved from http://regierungsforschung.de/neue-fallstudie-elterngeld-wie-agenda-setting-undneue-interessenkoalitionen-den-familienpolitischen-paradigmenwechselermoeglichten-von-martin-bujard/

Bundesministerium für Familie, Senioren, \& Frauen und Jugend. (2015). Fünfter Bericht zur Evaluation des Kinderförderungsgesetzes. Berlin. 
Bundesverband deutscher Zeitungsverleger. (2017). Die deutschen Zeitungen in Zahlen und Daten 2017. Retrieved from http://www.bdzv.de/

Ciccia, R., \& Bleijenbergh, I. (2014). After the Male Breadwinner Model?: Childcare Services and the Division of Labor in European Countries. Social Politics, 21(1), 50-79. doi:10.1093/sp/jxuoo2

Cunningham, M. (2001). The influence of parental attitudes and behaviors on children's attitudes toward gender and household labor in early adulthood. Journal of Marriage and Family, 63(1), 111-122. doi:10.1111/j.1741-3737.2001.00111.x

Davis, S. N., \& Greenstein, T. N. (2009). Gender Ideology: Components, Predictors, and Consequences. Annual Review of Sociology, 35(1), 87-105. doi:10.1146/annurev-soc070308-115920

Drasch, K. (2013). Educational Attainment and Family-Related Employment Interruptions in Germany: Do Changing Institutional Settings Matter? European Sociological Review, 29(5), 981-995. doi:10.1093/esr/jcso76

Ellingsæter, A. L., Kitterød, R. H., \& Lyngstad, J. (2017). Universalising Childcare, Changing Mothers' Attitudes: Policy Feedback in Norway. Journal of Social Policy, 46(o1), 149-173. doi:10.1017/Soo47279416000349

Federal Statistical Office. (2015). Kindertagesbetreuung regional 2015. Ein Vergleich aller 402 Kreise in Deutschland. Wiesbaden. Retrieved from http://www.statistikportal.de/statistik-portal/kita_regional.pdf

Festinger, L. (1957). A theory of cognitive dissonance (1. publ). Stanford, Calif.: Stanford Univ. Press.

Gangl, M., \& Ziefle, A. (2015). The Making of a Good Woman: Extended Parental Leave Entitlements and Mothers' Work Commitment in Germany. American Journal of Sociology, 121(2), 511-563. doi:10.1086/682419

Geyer, J., Haan, P., \& Wrohlich, K. (2015). The effects of family policy on maternal labor supply: Combining evidence from a structural model and a quasi-experimental approach. Labour Economics, 36, 84-98. doi:10.1016/j.labeco.2015.07.001

Google Trends. (2017). Websearch: „Kindergarten“ - Germany, January 2007 - December 2016. Retrieved from https://g.co/trends/ $5 \mathrm{Ij} 5 \mathrm{~L}$

Grunow, D., \& Evertsson, M. (Eds.). (2016). Couples' Transitions to Parenthood: Analysing Gender and Work in Europe. Cheltenham, UK: Edward Elgar Publishing.

Grunow, D., \& Müller, D. (2012). Kulturelle und strukturelle Faktoren bei der Rückkehr in den Beruf: ostdeutsche, westdeutsche und ost-west-mobile Mütter im Vergleich. Zeitschrift für Familienforschung, Sonderheft, (9), 55-77.

Haumann, W. (2014). Die Akzeptanzanalysen: Staatliche Familienleistungen aus Sicht der Bevölkerung. Vierteljahrshefte zur Wirtschaftsforschung, 83(1), 101-120. doi:10.379o/vjh.83.1.101

Hook, J. L. (2006). Care in Context: Men's Unpaid Work in 20 Countries, 1965-2003. American Sociological Review, 71(4), 639-66o. doi:10.1177/000312240607100406

Hook, J. L. (2015). Incorporating ,class' into work-family arrangements: Insights from and for Three Worlds. Journal of European Social Policy, 25(1), 14-31. doi:10.1177/0958928714556968

Huinink, J., Brüderl, J., Nauck, B., \& Walper, S. (2011). Panel Analysis of Intimate Relationships and Family Dynamics (pairfam): Conceptual framework and design. Journal of Family Research, 23(1), 77-100. 
International Network of Leave Policies \& Research. (2016). Total statutory leave (including additional childcare leaves). Retrieved from http://www.leavenetwork.org/

Kangas, O., \& Rostgaard, T. (2007). Preferences or institutions? Work family life opportunities in seven European countries. Journal of European Social Policy, 17(3), 240256. doi:10.1177/0958928707078367

Konietzka, D., \& Kreyenfeld, M. (2010). The growing educational divide in mothers' employment: An investigation based on the German micro-censuses 1976-2004. Work, Employment \& Society, 24(2), 260-278. doi:10.1177/0950017010362140

Kotsadam, A., \& Finseraas, H. (2011). The state intervenes in the battle of the sexes: Causal effects of paternity leave. Social Science Research, 40(6), 1611-1622. doi:10.1016/j.ssresearch.2011.06.011

Kraaykamp, G. (2012). Employment status and family role attitudes: A trend analysis for the Netherlands. International Sociology, 27(3), 308-329. doi:10.1177/0268580911423046

Kumlin, S., \& Stadelmann-Steffen, I. (2014). Citizens, policy feedback, and European welfare states. In S. Kumlin \& I. Stadelmann-Steffen (Eds.), Globalization and Welfare series. How Welfare States Shape the Democratic Public. Policy Feedback, Participation, Voting, and Attitudes (pp. 3-18). Cheltenham: Edward Elgar Publishing.

Min, J., Silverstein, M., \& Lendon, J. P. (2012). Intergenerational transmission of values over the family life course. Advances in Life Course Research, 17(3), 112-120. doi:10.1016/j.alcr.2012.05.001

Pedulla, D. S., \& Thébaud, S. (2015). Can We Finish the Revolution? Gender, WorkFamily Ideals, and Institutional Constraint. American Sociological Review, 8o(1), 116139. doi:10.1177/0003122414564008

Pettit, B., \& Hook, J. (2005). The Structure of Women's Employment in Comparative Perspective. Social Forces, 84(2), 779-801. doi:10.1353/sof.2006.0029

Petty, R. E., \& Cacioppo, J. T. (1986). Communication and Persuasion: Central and Peripheral Routes to Attitude Change. Springer Series in Social Psychology. New York, NY: Springer New York.

Rosenfeld, R. A., Trappe, H., \& Gornick, J. C. (2004). Gender and Work in Germany: Before and After Reunification. Annual Review of Sociology, 30(1), 103-124. doi:10.1146/annurev.soc.30.012703.110531

Schilling, M. (2014). Es sind noch Wünsche offen! Die frühkindliche Bildung, Betreuung und Erziehung im Jahr des Rechtsanspruchs für 1- und 2-Jährige. KomDat - Kommentierte Daten der Kinder- E Jugendhilfe, 3/14, 1-3.

Sjöberg, O. (2004). The Role of Family Policy Institutions in Explaining Gender-Role Attitudes: A Comparative Multilevel Analysis of Thirteen Industrialized Countries. Journal of European Social Policy, 14(2), 107-123. doi:10.1177/0958928704042003

Steiber, N., \& Haas, B. (2012). Advances in explaining women's employment patterns. Socio-Economic Review, 10(2), 343-367. doi:10.1093/ser/mwro39

Stets, J. E., \& Burke, P. J. (200o). Identity Theory and Social Identity Theory. Social Psychology Quarterly, 63(3), 224-237.

Strunz, E. (2015). Kindertagesbetreuung vor Ort - Der Betreuungsatlas 2014. Eine Analyse lokaler Unterschiede. Retrieved from http://www.akjstat.tudortmund.de/fileadmin/Analysen/Kita/Betreuungsatlas_2014_final.pdf 
Unterhofer, U., \& Wrohlich, K. (2017). Fathers, Parental Leave and Gender Norms. Discussion Papers, (1657), 1-27.

van Putten, A. E., Dykstra, P. A., \& Schippers, J. J. (2008). Just Like Mom? The Intergenerational Reproduction of Women's Paid Work. European Sociological Review, 24(4), 435-449. doi:10.1093/esr/jcno3o 
Table 1. Mean Attitudes and Differences across Waves of Mothers and Fathers in East and West Germany

\begin{tabular}{|c|c|c|c|c|c|c|c|c|}
\hline \multirow[t]{2}{*}{ Variable } & \multicolumn{4}{|c|}{ Mothers } & \multicolumn{4}{|c|}{ Fathers } \\
\hline & $\mathrm{W}_{1}$ & & $\mathrm{~W}_{7}$ & $\mathrm{~N}$ & $\mathrm{~W}_{1}$ & & $\mathrm{~W}_{7}$ & $\mathrm{~N}$ \\
\hline & & & \multicolumn{6}{|c|}{ West Germany } \\
\hline (1) Women should be more concerned about family than about career & 3.0 & $-0.13^{* * *}$ & 2.8 & 5051 & 2.9 & $-0.22^{* * *}$ & 2.7 & 3558 \\
\hline (2) A child under age 6 will suffer from having a working mother & 2.7 & $-0.32^{* * *}$ & 2.4 & 5036 & 3.1 & $-0.30^{* * *}$ & 2.8 & 3548 \\
\hline \multicolumn{9}{|l|}{ East Germany } \\
\hline (1) Women should be more concerned about family than about career & 2.6 & -0.08 & 2.5 & 2949 & 2.5 & -0.02 & 2.5 & 2269 \\
\hline (2) A child under age 6 will suffer from having a working mother & 2.0 & $-0.17^{* * *}$ & 1.9 & 2946 & 2.1 & -0.08 & 2.0 & 2261 \\
\hline
\end{tabular}

Note: Higher values indicate stronger agreement with the statements, i.e. more traditional attitudes.

Numbers shown in italics represent mean differences in attitudes among waves with $\mathrm{t}-\mathrm{Test} .{ }^{*} p<0.10,{ }^{* *} p<0.05,{ }^{* * *} p<0.01$

Source: pairfam, waves 2008-2015.

Table 2 Within-Person Changes in Attitude Scores across Waves in per cent

\begin{tabular}{|c|c|c|c|c|c|c|c|c|c|c|}
\hline & \multicolumn{5}{|c|}{ (1) Family vs. Career } & \multicolumn{5}{|c|}{ (2) Child will suffer } \\
\hline & Decrease & Increase & No change & Total & Individuals & Decrease & Increase & No change & Total & Individuals \\
\hline \multicolumn{11}{|c|}{ West Germany } \\
\hline Mothers & 29.25 & 26.91 & 43.84 & 100 & 2116 & 28.82 & $25 \cdot 59$ & $45 \cdot 59$ & 100 & 2115 \\
\hline Fathers & 29.82 & $25 \cdot 57$ & 44.61 & 100 & 1431 & 28.63 & 27.16 & 44.21 & 100 & 1432 \\
\hline \multicolumn{11}{|c|}{ East Germany } \\
\hline Mothers & 28.44 & 26.72 & 44.84 & 100 & 1219 & 24.57 & 23.02 & 52.41 & 100 & 1220 \\
\hline Fathers & 26.69 & $27 \cdot 36$ & $45 \cdot 95$ & 100 & 892 & $25 \cdot 51$ & 25.85 & 48.63 & 100 & 890 \\
\hline
\end{tabular}

Source: pairfam, waves 2008-2015. 
Table 3. Descriptive Statistics of Dependent and Independent Variables

\begin{tabular}{|c|c|c|c|c|c|c|c|c|}
\hline \multirow{3}{*}{ Variable } & \multicolumn{4}{|c|}{ West Germany } & \multicolumn{4}{|c|}{ East Germany } \\
\hline & \multicolumn{2}{|c|}{ Mothers } & \multicolumn{2}{|l|}{ Fathers } & \multicolumn{2}{|c|}{ Mothers } & \multicolumn{2}{|l|}{ Fathers } \\
\hline & $\mathrm{M} / \%$ & $\mathrm{SD}$ & $\mathrm{M} / \%$ & SD & $\mathrm{M} / \%$ & SD & $\mathrm{M} / \%$ & SD \\
\hline \multicolumn{9}{|l|}{ Individual level variables } \\
\hline Attitude family vs. career & 2.92 & 1.13 & 2.86 & 1.12 & 2.59 & 1.12 & 2.54 & 1.09 \\
\hline Attitude child suffers & 2.56 & 1.34 & 2.91 & 1.34 & 1.96 & 1.17 & 2.11 & 1.21 \\
\hline Age & 35.65 & 5.03 & 38.14 & 5.43 & 34.43 & 5.24 & 37.22 & 5.45 \\
\hline Cohort 1981-1983 & 0.27 & 0.44 & 0.16 & 0.37 & 0.38 & 0.48 & 0.22 & 0.41 \\
\hline Cohort 1971-1973 & 0.72 & 0.45 & 0.83 & 0.37 & 0.61 & 0.49 & 0.78 & 0.41 \\
\hline Migration background & 0.24 & 0.43 & 0.20 & 0.40 & 0.11 & 0.31 & 0.08 & 0.28 \\
\hline Education low (ref.) & 0.12 & 0.32 & 0.07 & 0.26 & 0.07 & 0.25 & 0.06 & 0.23 \\
\hline Education middle & 0.59 & 0.49 & 0.50 & 0.50 & 0.62 & 0.49 & 0.61 & 0.49 \\
\hline Education high & 0.30 & 0.46 & 0.43 & 0.49 & 0.31 & 0.46 & 0.33 & 0.47 \\
\hline Number of children: 1 & 0.30 & 0.46 & 0.28 & 0.45 & 0.39 & 0.49 & 0.34 & 0.47 \\
\hline Number of children: 2 & 0.47 & 0.50 & 0.48 & 0.50 & 0.45 & 0.50 & 0.49 & 0.50 \\
\hline Number of children: 3 or more & 0.23 & 0.42 & 0.23 & 0.42 & 0.16 & 0.37 & 0.17 & 0.38 \\
\hline Age of youngest child o-3 (ref.) & 0.42 & 0.49 & 0.44 & 0.50 & 0.44 & 0.50 & 0.44 & 0.50 \\
\hline Age of youngest child $4-6$ & 0.22 & 0.42 & 0.22 & 0.42 & 0.20 & 0.40 & 0.21 & 0.41 \\
\hline Age of youngest child 7- & 0.36 & 0.48 & 0.33 & 0.47 & 0.36 & 0.48 & 0.35 & 0.48 \\
\hline Living apart together (ref.) & 0.04 & 0.20 & 0.01 & 0.09 & 0.05 & 0.23 & 0.02 & 0.13 \\
\hline Cohabitation & 0.09 & 0.28 & 0.08 & 0.28 & 0.29 & 0.45 & 0.28 & 0.45 \\
\hline Married & 0.87 & 0.34 & 0.91 & 0.29 & 0.65 & 0.48 & 0.70 & 0.46 \\
\hline Net equivalence income (Euro) & 1720.07 & 1011.25 & 1791.58 & 1232.14 & $1508.5^{1}$ & 758.05 & $1567 \cdot 79$ & $765 \cdot 75$ \\
\hline Father employed & 0.96 & 0.20 & 0.96 & 0.20 & 0.93 & 0.26 & 0.92 & 0.27 \\
\hline Mother not employed (ref.) & 0.32 & 0.47 & 0.33 & 0.47 & 0.30 & 0.46 & 0.28 & 0.45 \\
\hline Mother part-time employment & 0.52 & 0.50 & 0.52 & 0.50 & 0.33 & 0.47 & 0.34 & 0.47 \\
\hline $\begin{array}{l}\text { Mother full-time employment } \\
\text { County level variables }\end{array}$ & 0.16 & 0.37 & 0.15 & 0.36 & 0.37 & 0.48 & 0.38 & 0.49 \\
\hline Childcare rate & 20.02 & 7.17 & 20.24 & 7.16 & 49.69 & 6.91 & 49.68 & 6.93 \\
\hline Childcare rate squared & 452.20 & 310.57 & 461.02 & 312.86 & $2517 \cdot 38$ & 683.71 & $2515 \cdot 74$ & 685.63 \\
\hline Rate of public servants per 10.000 & 129.46 & 46.73 & 128.21 & 47.07 & 134.15 & 56.27 & 136.22 & 55.28 \\
\hline Unemployment rate & 5.99 & 2.62 & 6.01 & 2.64 & 10.94 & 2.48 & 10.98 & 2.40 \\
\hline GDP per capita & 32.39 & 12.45 & 32.41 & 12.35 & 24.58 & $5 \cdot 72$ & 24.76 & 5.76 \\
\hline Index for low population density & 24.75 & 27.62 & 25.29 & 27.87 & 36.36 & 29.58 & 35.53 & 29.86 \\
\hline
\end{tabular}

Note: Higher attitude mean scores indicate stronger agreement with the statements, i.e. more traditional attitudes. Source: pairfam, waves 2008-2015. 
Table 4. Fixed Effects Regression Models for Mother's and Father's Attitudes

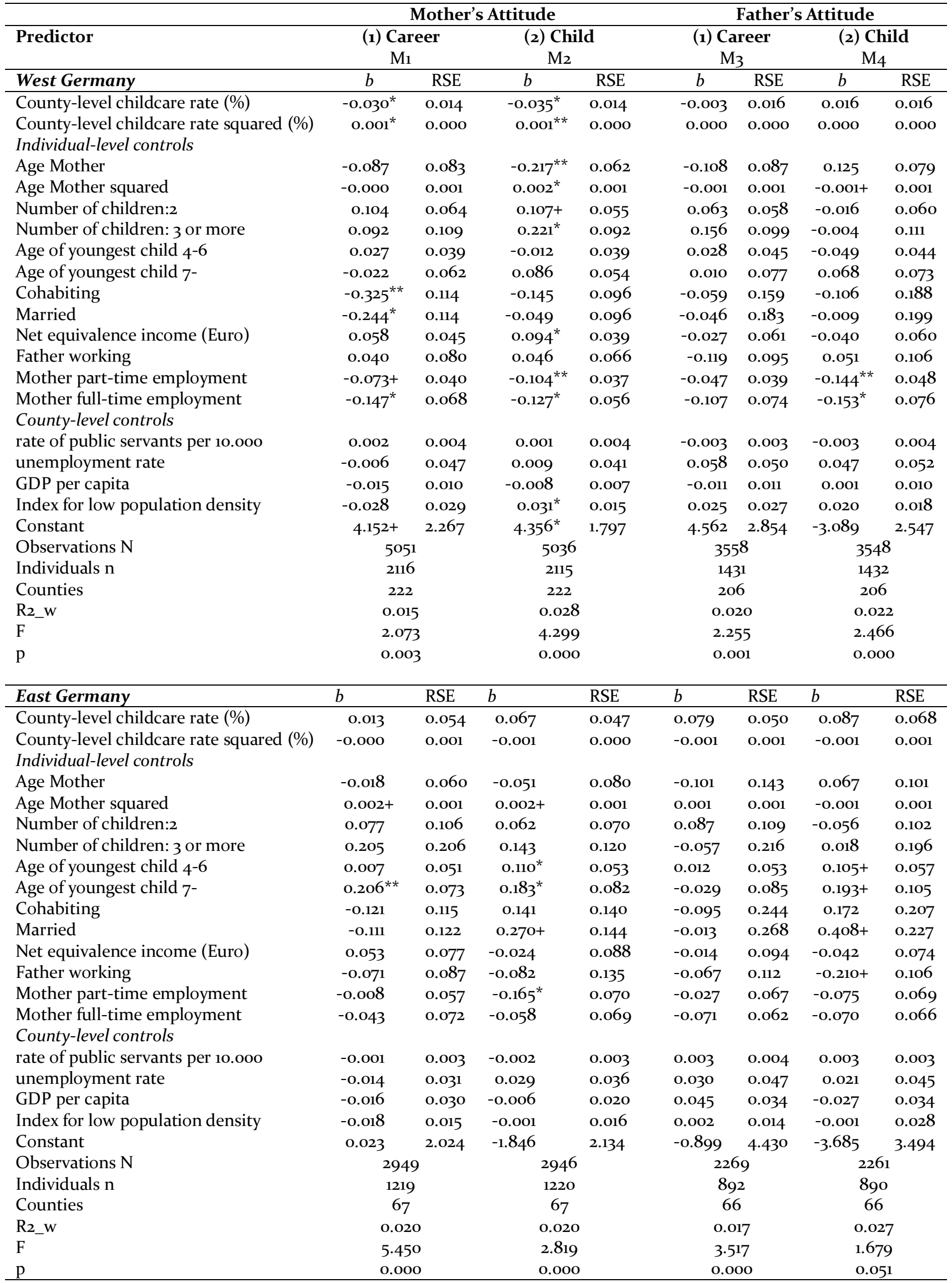

Note: Higher attitude scores indicate more traditional attitudes. All models include year dummy variables.

${ }^{+} p<0.10,{ }^{*} p<0.05,{ }^{* *} p<0.01$

Source: pairfam, waves 2008-2015. 
Table 5. Fixed Effects Regression Models for Mother's and Father's Attitudes considering Interactions with Education

\begin{tabular}{|c|c|c|c|c|c|c|c|c|}
\hline \multirow{3}{*}{$\begin{array}{l}\text { Predictor } \\
\text { West Germany }\end{array}$} & \multicolumn{4}{|c|}{ Mother's Attitude } & \multicolumn{4}{|c|}{ Father's Attitude } \\
\hline & \multicolumn{2}{|c|}{$\begin{array}{c}\text { (1) Career } \\
\text { M1 }\end{array}$} & \multicolumn{2}{|c|}{$\begin{array}{c}\text { (2) Child } \\
\mathrm{M}_{2}\end{array}$} & \multicolumn{2}{|c|}{$\begin{array}{c}\text { (1) Career } \\
\mathrm{M}_{3}\end{array}$} & \multicolumn{2}{|c|}{$\begin{array}{c}\text { (2) Child } \\
\mathrm{M}_{4}\end{array}$} \\
\hline & $b$ & RSE & $b$ & RSE & $b$ & RSE & $b$ & RSE \\
\hline County-level childcare rate (\%) & $-0.040^{*}$ & 0.015 & $-0.037^{*}$ & 0.016 & -0.002 & 0.019 & 0.019 & 0.023 \\
\hline County-level childcare rate squared (\%) & $0.001^{* *}$ & 0.000 & $0.001^{* *}$ & 0.000 & 0.000 & 0.000 & -0.000 & 0.001 \\
\hline College. X Childcare rate & $0.049^{*}$ & 0.022 & 0.008 & 0.018 & 0.022 & 0.019 & 0.011 & 0.027 \\
\hline College. X Childcare rate squared & -0.001 & 0.000 & -0.000 & 0.000 & -0.000 & 0.000 & 0.000 & 0.001 \\
\hline Constant & $3.808+$ & 2.290 & $4 \cdot 341^{*}$ & 1.800 & 4.026 & 2.919 & $-3 \cdot 486$ & 2.573 \\
\hline Observations $\mathrm{N}$ & \multicolumn{2}{|c|}{5051} & \multicolumn{2}{|c|}{5036} & \multicolumn{2}{|c|}{$355^{8}$} & \multicolumn{2}{|c|}{3548} \\
\hline Individuals $\mathrm{n}$ & \multicolumn{2}{|c|}{2116} & \multicolumn{2}{|c|}{2115} & \multicolumn{2}{|c|}{1431} & \multicolumn{2}{|c|}{1432} \\
\hline Counties & \multicolumn{2}{|c|}{222} & \multicolumn{2}{|c|}{222} & \multicolumn{2}{|c|}{206} & \multicolumn{2}{|c|}{206} \\
\hline R2_W & \multicolumn{2}{|c|}{0.019} & \multicolumn{2}{|c|}{0.028} & \multicolumn{2}{|c|}{0.026} & \multicolumn{2}{|c|}{0.025} \\
\hline $\mathrm{F}^{-}$ & \multicolumn{2}{|c|}{2.297} & \multicolumn{2}{|c|}{4.064} & \multicolumn{2}{|c|}{2.813} & \multicolumn{2}{|c|}{2.598} \\
\hline $\mathrm{P}$ & \multicolumn{2}{|c|}{0.001} & \multicolumn{2}{|c|}{0.000} & \multicolumn{2}{|c|}{0.000} & \multicolumn{2}{|c|}{0.000} \\
\hline East Germany & $b$ & RSE & $b$ & RSE & $b$ & RSE & $b$ & RSE \\
\hline County-level childcare rate (\%) & 0.037 & 0.065 & $0.114+$ & 0.060 & $0.085^{+}$ & 0.049 & 0.109 & 0.067 \\
\hline County-level childcare rate squared (\%) & -0.001 & 0.001 & $-0.001+$ & 0.001 & $-0.001+$ & 0.001 & $-0.001+$ & 0.001 \\
\hline College. X Childcare rate & -0.056 & 0.090 & $-0.158^{*}$ & 0.073 & -0.012 & 0.092 & -0.034 & 0.069 \\
\hline College. X Childcare rate squared & 0.001 & 0.001 & $0.002 *$ & 0.001 & 0.000 & 0.001 & 0.001 & 0.001 \\
\hline Constant & -0.496 & 1.964 & -2.046 & 2.191 & -1.066 & 4.483 & $-4 \cdot 537$ & -0.496 \\
\hline Observations $\mathrm{N}$ & \multicolumn{2}{|c|}{2949} & & & & & & \\
\hline Individuals $\mathrm{n}$ & & & & & & & & \\
\hline Counties & & & & & & & & \\
\hline R2_W & & & & & & & & \\
\hline $\mathrm{F}$ & & & & & & & & \\
\hline $\mathrm{P}$ & 0. & & 0. & & & & & \\
\hline
\end{tabular}

Note: Higher attitude scores indicate more traditional attitudes. All models include: Mother's age and age squared, number of children, age of the youngest child, marital status, net equivalence income, father's employment, year dummies, the percentile of public servants, unemployment rate, GDP per capita and the index for low population density.

${ }^{+} p<0.10,{ }^{*} p<0.05,{ }^{* *} p<0.01,{ }^{* * *} p<0.001$

Source: pairfam, waves 2008-2015. 


\section{Appendix}

Figure A1. Predictive Margins FOr WeSt German Mothers

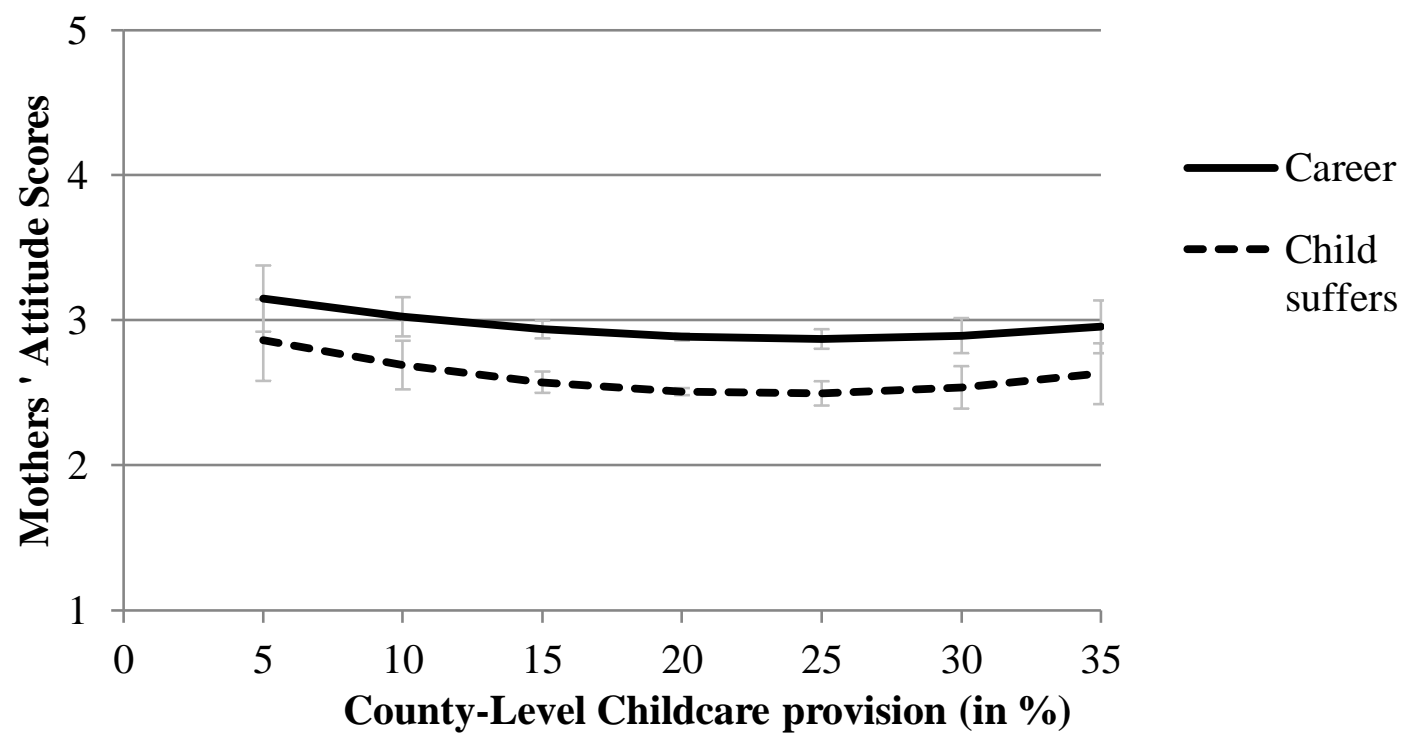

Note: Higher values indicate stronger agreement with the statements, i.e. more traditional attitudes.

Table A1. Fixed Effects Regression Models for West German Mother's Attitudes including Take-Up of Formal Childcare

\begin{tabular}{lllllllll}
\hline Predictor & \multicolumn{3}{c}{ (1) Career } & \multicolumn{3}{c}{ (2) Child } \\
& \multicolumn{2}{c}{ M1 } & \multicolumn{2}{c}{ M2 } & \multicolumn{2}{c}{ M3 } & \multicolumn{2}{c}{ M4 } \\
\hline & $b$ & RSE & $b$ & RSE & $b$ & RSE & $b$ & RSE \\
\hline Childcare \% & -0.032 & 0.021 & -0.032 & 0.021 & -0.015 & 0.016 & -0.015 & 0.016 \\
Childcare squared \% & 0.000 & 0.000 & 0.000 & 0.000 & 0.000 & 0.000 & 0.000 & 0.000 \\
Childcare Take-up Part-time & & & -0.055 & 0.054 & & & -0.038 & 0.047 \\
Childcare Take-up Part-time & & & -0.033 & 0.060 & & & -0.019 & 0.055 \\
Constant & 3.910 & 3.826 & 3.676 & 3.766 & $5.037^{+}$ & 2.877 & $4.888^{+}$ & 2.927 \\
Observations N & 3430 & & 3430 & & 3421 & & 3421 & \\
Individuals n & 1697 & & 1697 & & 1698 & & 1698 & \\
Counties & 216 & & 216 & & 216 & & 216 & \\
R2_w & 0.016 & & 0.017 & & 0.021 & & 0.022 & \\
F & 2.076 & & 1.999 & & 2.108 & & 1.920 \\
p & 0.006 & & 0.007 & & 0.005 & & 0.010 \\
\hline
\end{tabular}

Note: Higher values indicate more traditional attitudes. All models include: Mother's age and age squared, number of children, age of the youngest child, marital status, net equivalence income, father's employment, year dummies, the percentile of public servants, unemployment rate, GDP per capita and the index for low population density.

${ }^{+} p<0.10,{ }^{*} p<0.05,{ }^{* *} p<0.01,{ }^{* * *} p<0.001$

Source: pairfam, waves 2008-2015. 